\title{
A Brief Review of the Rise and Biological Research of Deep Underground Medicine in China
}

\author{
Ying Xiong ${ }^{1}$ and Michael Zhengmeng Hou ${ }^{1,2 *}$ \\ ${ }^{1}$ Institute of Subsurface Energy Systems, Clausthal University of Technology, Germany \\ ${ }^{2}$ Sino-German Energy Research Center, Sichuan University, China
}

*Corresponding author: Michael Zhengmeng Hou, Institute of Subsurface Energy Systems, Clausthal University of Technology, Germany

\begin{tabular}{|c|c|}
\hline ARTICLE INFO & ABSTRACT \\
\hline Received: 㓞 April 09, 2020 & \multirow{4}{*}{$\begin{array}{l}\text { The conception of deep underground medicine was firstly proposed in China in } 2015 \text {, } \\
\text { which is a multidisciplinary approach to medical research involving the geology, } \\
\text { environment and biochemistry. Its main objective is to utilize the medical effects of } \\
\text { some inherent characteristics of underground environment to improve and cure human } \\
\text { diseases. Karst caves, salt and other mines caves could be available underground space. } \\
\text { The development of deep underground medicine is of great strategic significance for } \\
\text { the sustainable utilization of huge underground space and transition of mine resources. } \\
\text { This paper provides a brief review of the history and research advances of deep } \\
\text { underground medicine in China, giving special focus on the concepts, deep underground } \\
\text { laboratory construction, preliminary results of cell culture experiments and miners } \\
\text { questionnaire studies in this emerging discipline. Based on the concepts, goals and } \\
\text { current status, the potential and future research emphasis of the deep underground } \\
\text { medicine are also presented. }\end{array}$} \\
\hline Published: 慧 April 24, 2020 & \\
\hline $\begin{array}{l}\text { Citation: Ying X, Michael ZH. A Brief } \\
\text { Review of the Rise and Biological Research } \\
\text { of Deep Underground Medicine in China. } \\
\text { Biomed J Sci \& Tech Res 27(2)-2020. BJSTR. } \\
\text { MS.ID.004473. }\end{array}$ & \\
\hline $\begin{array}{l}\text { Keywords: Deep Underground Medicine; } \\
\text { Mine Resources Transition; Cell Growth; } \\
\text { Miners' Health }\end{array}$ & \\
\hline
\end{tabular}

\section{Introduction}

In recent years, the exploration and utilization of underground space has aroused wide attention in China. Apart from conventional discipline such as oil and gas exploitation, geothermal and other mining resources exploitation, there is an increasing awareness regarding the influence of extreme underground environment on human physical symptoms and mental health [1,2]. Xie et al. (2015) put forward the conception of deep underground medicine which has subsequently gained wide attention and recognition [3]. In addition to highlight the important role of deep underground in medical research, this emerging discipline has also expanded the scope and idea of the development and utilization of underground space. It brings new possibilities for the industrial structure adjustment of mining-based city, reuse of idle mine as well as creating new economic and social benefits [4,5]. Over the past 5 years, preliminary progress has been made, such as the establishment of deep underground medicine discipline and associated research institutions, site selection of underground medical laboratories, and initial control experiments on cell culture and growth dynamics under actual underground environment
$[6,7]$. The complex interpenetration of multidisciplinary approach, however, place various uncertainties and challenges to the underground medical research. Thus, the practical application of deep underground medicine is still in its infancy. The effects and mechanism of extreme underground environmental factors (depth, air pressure, low-radiation, claustrophobic, rock types, microorganisms with its growth kinetics) on human physical and mental health is still not very clear. Based on the present literatures and public reports, the rise, research advance and future prospects are reviewed in this paper.

\section{Conception and Objective}

The earliest reports of humans using the underground environment for disease treatment or medical research dated back more than 100 years. It started in eastern Europe, then prevailed in eastern and central Europe, and was primarily used to treat respiratory diseases $[8,9]$. Similar to the Chinese concept of Halotherapy, this discipline was known as Speleotherapy [10], which currently refers to the treatment of diseases by using some 
of the inherent characteristics of the underground space and environment. These underground spaces can be diverse, including karst caves, salt or mines caves, road tunnel, and even radioactive nuclear waste repository. For instance, the tunnels of the Solotvyno Salt Mine in Ukraine have made for an unconventional hospital ward. Patients with various bronchial blockages, asthma 55 and breathing problems are sent to the mines to suck up the curative air [11]. Laboratori 56 Nazionali del Gran Sasso (LNGS) in Italy is the largest underground laboratory in the world 57 devoted to neutrino and astroparticle physics. The researchers also found that cell growth 58 slowed in this deep $(1,400 \mathrm{~m})$, low-radiation environment [12], which may arouse interest of 59 the longevity for human beings living in the deep environment.

In 2015, the conception of deep underground medicine was proposed by Prof. Xie and was defined as a specialized discipline to study the pathological effects and mechanisms of underground environmental conditions at different depths on living organisms with their physiological and psychological response; as well as the explore of strategies for dealing with harmful factors and the safeefficient use of beneficial factors in the service of human society [3]. Compared with the Speleotherapy, this new conception emphasizes the comprehensive research of multiple disciplines, rather than the single medical research. Specifically, it aims to

a) Qualitatively and quantitatively characterize the various parameters for underground environment (e.g. temperature, radiation, air pressure, rock type, microorganisms) and its connections with human physiology, psychology, and pathology.

b) To explore the beneficial elements for human health by theoretical basis and clinical studies of model-organisms.

c) To promote current medical technology by the new findings.

d) To establish a medical theory for further research and utilizing of deep underground space with its associated resources.

\section{Deep Underground Laboratory and Biological Re- search}

Based on the comprehensive evaluation of various effects such as geological conditions, mine types and underground space environment, the first deep underground medical research base and laboratory was set up in a goaf that is under $1,470 \mathrm{~m}$ of rock and $820 \mathrm{~m}$ below sea level. This laboratory was jointly funded by the West China Hospital of Sichuan University and Jiapigou Minerals limited Corporation, China National Gold Group Corporation [3]. Subsequently, a 4-day controlled experiment was carried out in this laboratory, in which three different types of cells were cultured respectively in the underground environment of $1,470 \mathrm{~m}$ and the same conditions on the ground. The three types cells are Chinese hamster V79 cells, laryngeal squamous cell carcinoma PD-LSC-1 cells and human thyroid follicular epithelial HTFEC cells. Expectedly, the experiment found that the growth of all cells incubated in the underground environment was delayed [6]. These initial findings provide enlightenment and new ideas for the study of human metabolism and cell aging, especially the possibility and effects of pure deep underground environment with low radiation or solar cosmic rays on the slowing down of human metabolism and cells growth. However, further experiments and research projects are needed to be continuing to reveal its mechanism and universal significance of these findings for the health of humans and the development of other organisms.

Another cross-section questionnaire study was recently conducted at China Pingmei Shenma mine complex by Xie et al. (2020) to reveal the physical symptom changes and their correlations with mental health status in deep underground miners. A total of 286 miners are involved in this questionnaire, which report prevalent physical or mental problems including fatigue (40.22\%), hearing loss (34.96\%) and tinnitus (31.58\%) after a long time working in extreme underground environments. The major adverse environment factors are moisture (62.03\%), dim light (45.86\%) and high temperature $(42.11 \%)$. The researchers also found that with increasing depth below ground, air pressure, relative humidity, $\mathrm{CO}_{2}$ concentration and temperature rose, while total gamma radiation dose-rate decreased $[7,13]$. Therefore, it is of great significance to identify these adverse environmental factors and to establish the relationship between environmental, physical and mental symptoms for the purpose of improving underground working environment.

\section{Conclusion and Prospect}

As an emerging research field in China in recent years, deep underground medicine is a multidisciplinary medical system involving geology, environment and biochemistry. Over the past 5 years, the conception, contents and objectives have been clearly determined, and some preliminary progress and initial data have been obtained regarding cell culture experiments and laboratory construction in underground environment. However, the current methods for deep underground biological research are still relatively limited and the findings are less reported in publications. China has abundant available underground space, including a large number of karst caves, salt and mines caves etc., which provide the basic and favorable conditions for the development of deep underground medicine. Further studies regarding more control experiments and comparative analysis should be carried out in order to popularize the research findings as well as its universal significance.

Meanwhile, there is still a lack of unified understanding on the mechanism of deep underground medical treatment. The research on the physiological and pathological effects of underground environment on living organisms (from cells to animals) needs to be strengthened to lay a theoretical foundation for the further development and utilization of underground space. In addition, it is necessary to develop a set of deep underground standards in 
terms of diverse environment factors, because not all underground environments are suitable for medical treatment and not all patients are suitable for this method. Finding out the beneficial factors and avoiding the adverse factors would be critical to understand the applicability of diseases and patients.

\section{Acknowledgement}

This study was jointly supported by the China Scholarship Council (No. 201908080005) and Clausthal University of Technology. We acknowledge support by Open Access Publishing Fund of Clausthal University of Technology.

\section{Conflict of Interest}

\section{None}

\section{References}

1. Amponsah Tawiah K, Leka S, Jain A, Hollis D, Cox T (2014) The impact of physical and psychosocial risks on employee well-being and quality of life: The case of the mining industry in Ghana. Safety Science 65: 28-35.

2. Han L, Li Y, Yan W, Xie L, Wang S, et al. (2018) Quality of life and influencing factors of coal miners in Xuzhou, China. Journal of Thoracic Disease 10(2): 835.

3. Xie H, Liu J, Gao M, Wan X, Liu S, et al. (2018) The research advancement and conception of the deep-underground medicine. Journal of Sichuan University (Medical Science Edition) 49(2): 163-168.

4. Xie H, Gao F, Ju Y, Zhang R, Gao M, et al. (2017) Novel idea and disruptive technologies for the exploration and research of deep earth. Advanced Engineering Sciences 49(1): 1-8.

ISSN: 2574-1241

DOI: $10.26717 /$ BJSTR.2020.27.004473

Michael Zhengmeng Hou. Biomed J Sci \& Tech Res

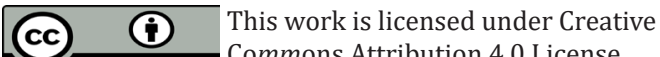

Submission Link: https://biomedres.us/submit-manuscript.php
5. Xie H, Gao M, Zhang R, Xu H, Wang Y, et al. (2017) The subversive idea and its key technical prospect on underground ecological city and ecosystem. Chinese Journal of Rock Mechanics and Engineering 36(6): 1301-1313.

6. Liu J, Ma T, Liu Y, Zou J, Gao M, et al. (2018) History, advancements, and perspective of biological research in deep underground laboratories: A brief review. Environment International 120: 207-214.

7. Xie H, Liu J, Gao M, Liu Y, Ma T, et al. (2020) Physical symptoms and mental health status in deep underground miners: A cross-sectional study. Medicine 99: 9(e19294).

8. Horvath T (1986) Speleotherapy: a special kind of climatotherapy, its role in respiratory rehabilitation. International Rehabilitation Medicine 8(2): 90-92.

9. Chervinskaya AV, Zilber NA (1995) Halotherapy for treatment of respiratory diseases. Journal of Aerosol Medicine 8(3): 221-232.

10. Li X, Yang X, Xiang X, Shi D (2014) Review of foreign research on speleotherapy. Carsologica Sinica 33(3): 379-385.

11. Li A (2015) Common diseases and natural therapy series of six: strange cave therapies. Health Life 4 (151): 38-39.

12. Satta L, Antonelli F, Belli M, Sapora O, Simone G, et al. (2002) Influence of a low background radiation environment on biochemical and biological responses in V79 cells. Radiation and Environmental Biophysics 41(3): 217-224.

13. Liu J, Liu Y, Ma T, Gao M, Zhang R, et al. (2019) Subjective perceptions and psychological distress associated with the deep underground: A crosssectional study in a deep gold mine in China. Medicine 98: 22(e15571).

\begin{tabular}{ll} 
BIOMEDICAL & Assets of Publishing with us \\
RESEARCHES & - Global archiving of articles \\
\hline ISS: $2574-1241$ & - Immediate, unrestricted online access \\
\hline
\end{tabular}

